Chapter 4

\title{
Phosphoric Acid Industry: Problems and Solutions
}

\author{
Benjamín Valdez Salas, Michael Schorr Wiener and \\ Juan Ricardo Salinas Martinez
}

Additional information is available at the end of the chapter

http://dx.doi.org/10.5772/intechopen.70031

\begin{abstract}
Phosphoric acid (PA) is an important industrial chemical used as an intermediate in the fertilizer industry, for metal surface treatment in the metallurgical industry and as an additive in the food industry. The PA industry is spread out worldwide in Europe, Asia and America, including countries that operate phosphate rock (PR) mines and produce PA, phosphatic fertilizers and phosphate-based products.
\end{abstract}

Keywords: corrosion, phosphoric acid, phosphate rock, erosion-corrosion, WPA

\section{Introduction}

Phosphoric acid (PA) is an important industrial chemical used as an intermediate in the fertilizer industry, for metal surface treatment in the metallurgical industry and as an additive in the food industry. The PA industry is spread out worldwide in Europe, Asia and America, including countries that operate phosphate rock (PR) mines and produce PA, phosphatic fertilizers and phosphate-based products. The PR reserves; worldwide are shown in Figure 1.

Acids, such as phosphoric $\left(\mathrm{H}_{3} \mathrm{PO}_{4}\right)$, sulfuric $\left(\mathrm{H}_{2} \mathrm{SO}_{4}\right)$, nitric $\left(\mathrm{HNO}_{3}\right)$, hydrochloric $(\mathrm{HCl})$ and acetic $\left(\mathrm{CH}_{3} \mathrm{COOH}\right)$ acids, are broadly applied in many industries: chemical, fertilizers, mineral leaching, water purification, petroleum refining, food and metal production [1-3]. 


\title{
World Phosphate Rock Reserves
} 65,000 million tonnes

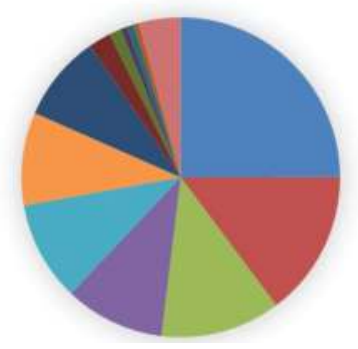

\author{
EChina, 3700 \\ n Algeria, 2200 \\ = Syria, 1800 \\ - Jordan, 1500 \\ = South Africa, 1500 \\ $=$ USA, 1400 \\ - Russia, 1300 \\ - Brazil, 340
}

Figure 1. World phosphate rock reserves. Source: USSG mineral commodity summary 2011.

\section{The world phosphate rock (PR) market}

PR is the raw material for the production of the diverse types of PA. It is mined in several continents and countries, as recorded in Table $\mathbf{1 .}$

\begin{tabular}{ll}
\hline Countries & Production (in `000 metric tons) \\
\hline China & 65,000 \\
USA & 26,100 \\
Morocco and Western Sahara & 26,000 \\
Tunisia & 10,000 \\
Jordan & 7600 \\
Brazil & 6000 \\
Egypt & 5500 \\
Israel & 5000 \\
Australia & 3000 \\
Syria & 2800 \\
South Africa & 2300 \\
Algeria & 2000 \\
Togo & 800 \\
Canada & 700 \\
Senegal & 650 \\
Others Countries & 9500 \\
\hline
\end{tabular}

Source: USSG Mineral Commodity Summary 2011.

Table 1. World producers of phosphate rock. 


\section{Phosphate rock: types and chemical composition}

Apatite is the most important PR applied in the production of industrial and food grade PA. It is mainly of the fluoride and hydroxide type. Both rocks contain many impurities: fluoride $\left(\mathrm{F}^{-}\right)$, chloride $\left(\mathrm{Cl}^{-}\right)$, iron and aluminum oxides $\left(\mathrm{Fe}_{2} \mathrm{O}_{3}, \mathrm{Al}_{2} \mathrm{O}_{3}\right)$; pyrites (ferrous sulfide, $\mathrm{FeS}$ ) and fossilized organic matter. These interfere with production procedures, impair the PA quality and enhance corrosion and deterioration of metallic and plastic materials used for fabrication of equipment and rubber linings for reactor walls [4-6]. The chemical composition (in weight percentage) of PRs from different sources is given in Table 2 [7].

\section{Phosphoric acid: production processes and industrial plants}

The main wet processes for PA production are:

a. The Wet process acid (WPA) uses sulfuric acid to convert the PR into PA and

b. The solvent extraction (SX) process, where the PR is acidulated with $\mathrm{HCl}$ and PA is separated applying an industrial alcohol as solvent.

\subsection{The WPA consists of three main stages}

Acidulation of $\mathrm{PR}$ by $\mathrm{H}_{2} \mathrm{SO}_{4}$; the overall reaction with fluoroapatite is usually expressed as:

$$
\mathrm{Ca}_{10}\left(\mathrm{PO}_{4}\right)_{6} \mathrm{~F}_{2}+10 \mathrm{H}_{2} \mathrm{SO}_{4} \rightarrow 10 \mathrm{CaSO}_{4}+6 \mathrm{H}_{3} \mathrm{PO}_{4}+2 \mathrm{HF}
$$

The hydrogen fluoride reacts with any active silica present to form silicon tetrafluoride:

$$
4 \mathrm{HF}+\mathrm{SiO}_{2} \rightarrow \mathrm{SiF}_{4}+2 \mathrm{H}_{2}
$$

It volatilizes as such or hydrolyzes to fluorosilicic acid and forms silica deposits:

$$
3 \mathrm{SiF}_{4}+2 \mathrm{H}_{2} \mathrm{O} \rightarrow 2 \mathrm{H}_{2} \mathrm{SiF}_{6}+\mathrm{SiO}_{2}
$$

During the acidulation, thick slurry is formed containing 30\% of solid particles, mainly gypsum $\left(\mathrm{CaSO}_{4}\right)$ and unreacted PR components.

Filtration is performed to separate the solid particles from the filter acid, $30 \% \mathrm{w} / \mathrm{w} \mathrm{P}_{2} \mathrm{O}_{5}(50 \% \mathrm{PA}$ ).

Concentration is performed by evaporation of the filter acid to merchant grade PA, $54 \%$ w/w $\mathrm{P}_{2} \mathrm{O}_{5}$ (70\% PA).

The $\mathrm{H}_{2} \mathrm{SO}_{4}$ reacts with any calcium carbonate and heavy metal oxides present in most rocks:

$$
\begin{gathered}
\mathrm{CaCO}_{3}+\mathrm{H}_{2} \mathrm{SO}_{4} \rightarrow \mathrm{CaSO}_{4}+\mathrm{CO}_{2}+\mathrm{H}_{2} \mathrm{O} \\
\mathrm{Fe}_{2} \mathrm{O}_{3}+3 \mathrm{H}_{2} \mathrm{SO}_{4} \rightarrow \mathrm{Fe}_{2}\left(\mathrm{SO}_{4}\right)_{3}+3 \mathrm{H}_{2} \mathrm{O} \\
\mathrm{Al}_{2} \mathrm{O}_{3}+3 \mathrm{H}_{2} \mathrm{SO}_{4} \rightarrow \mathrm{Al}_{2}\left(\mathrm{SO}_{4}\right)_{3}+3 \mathrm{H}_{2} \mathrm{O}
\end{gathered}
$$




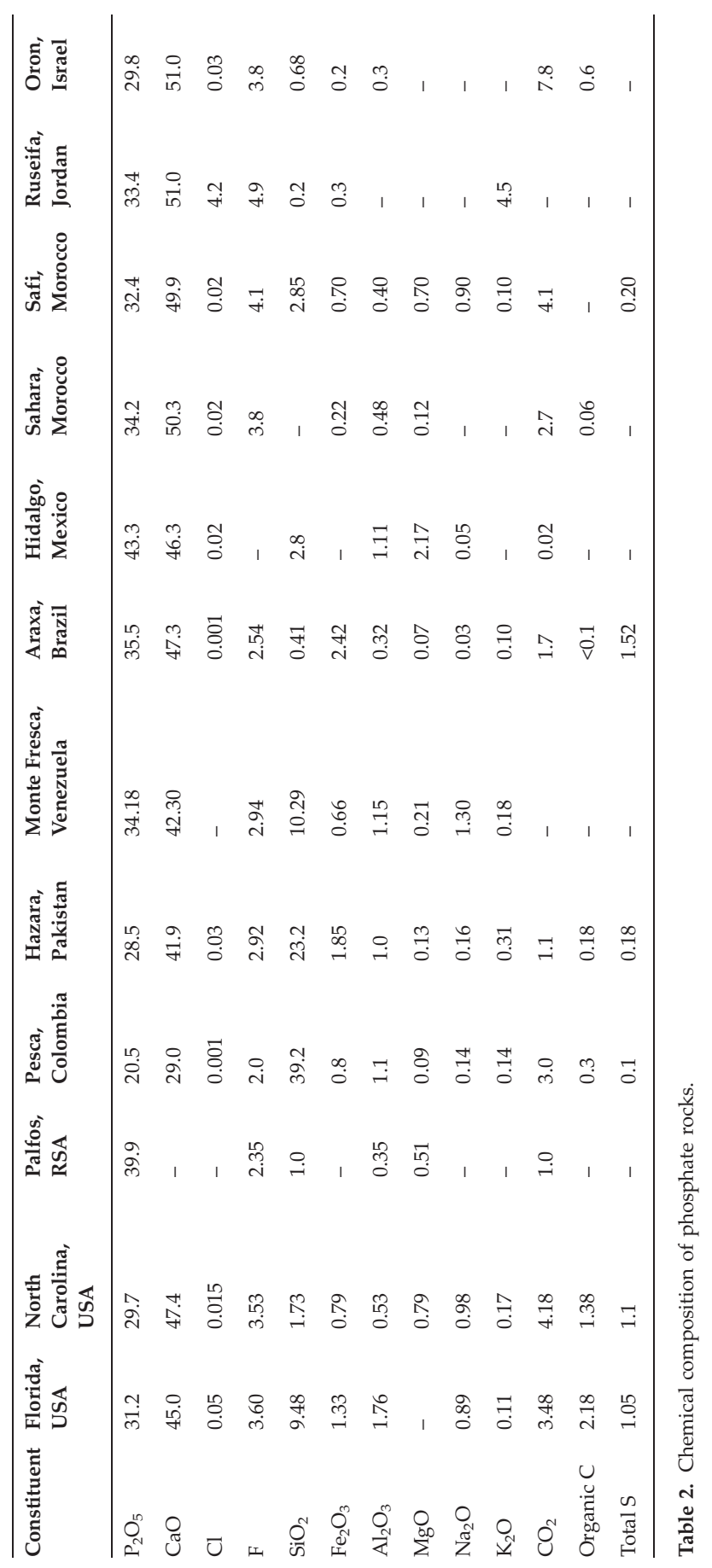




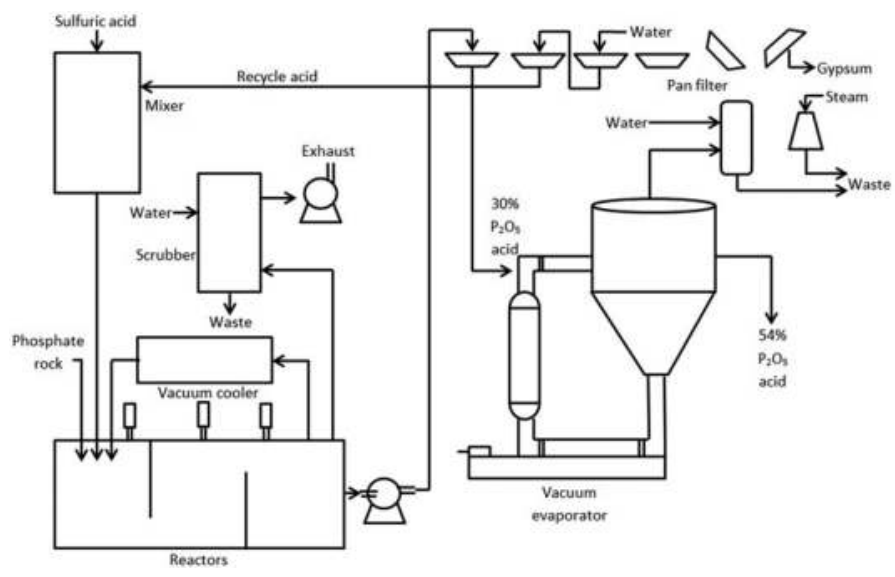

Figure 2. Typical wet process industrial plant.

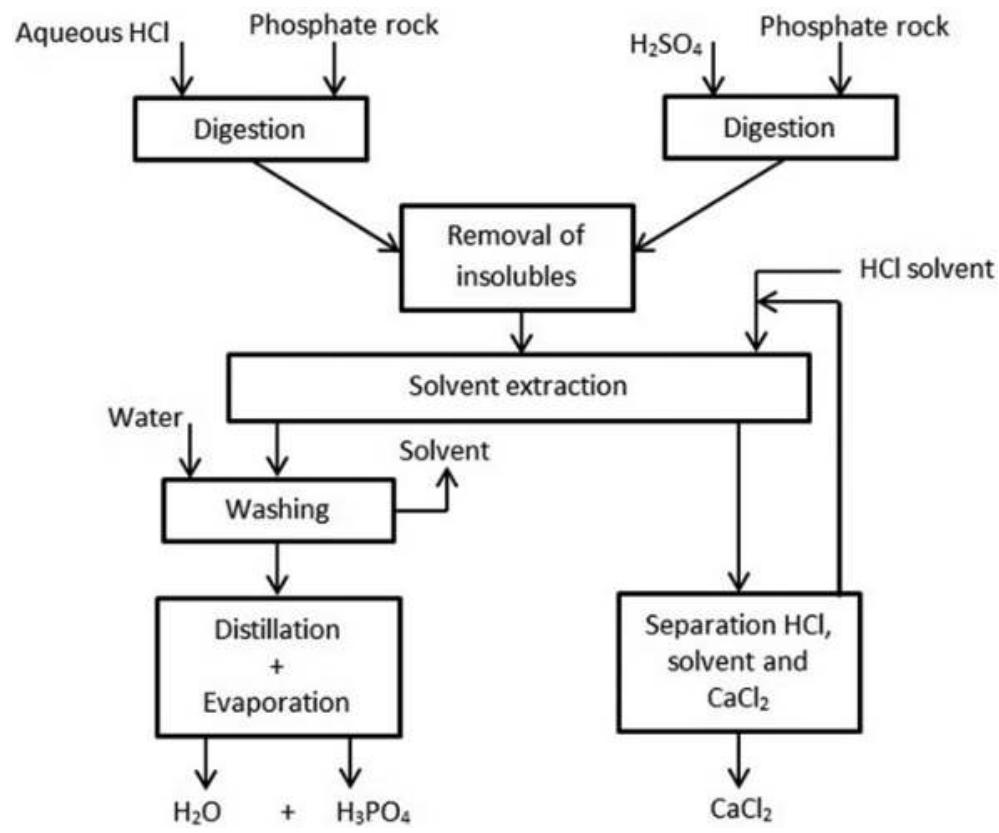

Figure 3. Diagram of solvent extraction process.

PRs contain chlorides, such as $\mathrm{NaCl}$, which yields $\mathrm{HCl}$ :

$$
2 \mathrm{NaCl}+\mathrm{H}_{2} \mathrm{SO}_{4} \rightarrow \mathrm{Na}_{2} \mathrm{SO}_{4}+2 \mathrm{HCl}
$$

The PR industry requires large amounts of water to wash its ore and to dissolve corrosive chlorides. These Negev desert waters were investigated to characterize their scaling, corrosion 
and fouling mechanisms, which affect the water system [8]. A critical unit is the huge reactor into which $\mathrm{PR}$ and $\mathrm{H}_{2} \mathrm{SO}_{4}$ are fed (Figure 2).

\subsection{The solvent extraction process}

$\mathrm{PR}$ is reacted with $\mathrm{HCl}$ to form an aqueous reaction mixture comprising $\mathrm{PA}$ and $\mathrm{CaCl}_{2}$ :

$$
\mathrm{Ca}_{3}\left(\mathrm{PO}_{4}\right)_{2}+6 \mathrm{HCl} \rightarrow 2 \mathrm{H}_{3} \mathrm{PO}_{4}+3 \mathrm{CaCl}_{2}
$$

In this version, the slurries obtained by treatment with $\mathrm{H}_{2} \mathrm{SO}_{4}$ (wet process) and with $\mathrm{HCl}$ (SX process) are mixed, and subsequently, the PA is extracted with an aliphatic alcohol (Figure 3) [9-11].

\section{Phosphate rock impurities: influence on production}

PR is the principal source of dissolved and suspended impurities in wet process phosphoric acid (WPA). Other impurities, such as $\mathrm{Cl}^{-}$may be introduced in process water, particularly brackish water. Sometimes contaminated $\mathrm{H}_{2} \mathrm{SO}_{4}$ obtained from the hydrometallurgy industry introduces additional impurities. The impurities impart undesired color and turbidity to the WPA and increase the corrosiveness of $\mathrm{PA} \mathrm{Cl}^{-}$and $\mathrm{F}^{-}$are particularly corrosive, and other impurities that affect corrosion are $\mathrm{SiO}_{2}, \mathrm{Al}_{2} \mathrm{O}_{3}$, alkali metal salts, $\mathrm{SO}_{4}{ }^{-}, \mathrm{S}^{-}$, organic matter and oxidizing agents. The corrosivity of a specific impurity depends on its chemical nature, the concentration of its active species, and its interaction with other acid constituents and with the surface of the specific metal $[12,13]$.

In addition to affecting corrosion, some impurities change the density and viscosity of the acid and form acid sludge and sediments. In contact with metallic surfaces, these sediments may influence the corrosion behavior of the metal by forming deposits that promote localized corrosion.

\subsection{Influence of chloride ion}

The chloride ion $\left(\mathrm{Cl}^{-}\right)$in PA comes from phosphate ores in which it is present as an alkali metal chloride, such as $\mathrm{NaCl}$. It may be removed by washing with fresh water, but it may also come from the wash water since seawater is sometimes used for washing the PR or forming rising tanks or cargo holds. The $\mathrm{Cl}^{-}$content then can rise to a dangerous level. Chloride may also occur in the apatite itself, sometimes as a water-insoluble salt or as an oxychloride formed during calcination of the PR.

Chloride contamination may also result from handling and storing of raw materials. In many fertilizer plants, PR and muriate of potash (MOP, the most common source of potassium used in agriculture as potassium chloride) are unloaded with the same equipment and stored in bulk in the same building. Small amounts of MOP often are left in elevators and conveyors and may be mixed with the PR subsequently handled in the equipment. 
The corrosivity of the halogen acids, $\mathrm{HCl}$ and $\mathrm{HF}$, and of the halide ions $\mathrm{Cl}^{-}$and $\mathrm{F}^{-}$in strong mineral oxygen-acids, such as $\mathrm{H}_{3} \mathrm{PO}_{4}$ and $\mathrm{H}_{2} \mathrm{SO}_{4}$, is related to the physicochemical properties of the halogens, and the electronegativity, ion size, and ionic character of the HX molecule indicate their high chemical reactivity. Chloride ion is adsorbed on metal surfaces and replaces adsorbed oxygen or water molecules. This shifts the potential of the metal to more active (electronegative) values and causes breakdown of the passive state, mainly at elevated temperatures, which leads to the formation of pits. During attack of stainless steel (SS), chlorides of iron, nickel and chromium are formed; these are highly soluble in PA because of its complexing of cations of the transition group elements [14].

The values of the electrochemical parameters of the anodic polarization curve, such as $i_{C C}$ which indicates corrosion activity, increase with increasing $\mathrm{Cl}^{-}$concentration.

\subsection{Influence of fluoride ion}

The $\mathrm{CaF}_{2}$ constituent of the fluoroapatite of $\mathrm{PR}$ reacts with $\mathrm{H}_{2} \mathrm{SO}_{4}$ during acidulation to produce $\mathrm{HF}$ which may form $(\mathrm{HF})_{2}$ and $\mathrm{F}^{-}$ions, depending on the hydrogen ion activity of the solution according to the equilibrium:

$$
\underset{\text { HF dimer }}{(\mathrm{HF})_{2}} \rightleftharpoons \underset{\text { Free HF }}{2 \mathrm{HF}} \rightleftharpoons \underset{\text { Hydrofluoride ion }}{\mathrm{HF}_{2}^{-}+\mathrm{H}^{+}} \rightleftharpoons \underset{\text { Fluoride ion }}{2 \mathrm{~F}^{-}}+\underset{\text { Hydrogen ion }}{2 \mathrm{H}^{+}}
$$

Dissolved aluminum compounds form acid-soluble aluminum fluoride complexes, for example, $\left(\mathrm{AlF}_{6}\right)^{-3}$. Other reactions that decrease corrosion include formation of partially soluble metals fluoride complexes with $\mathrm{Fe}^{+3}, \mathrm{Mg}^{+2}, \mathrm{Ca}^{+2}$ and $\mathrm{Na}^{+}$, and formation of insoluble fluoroaluminates and fluorosilicates that settle on metallic surfaces, such as $\mathrm{Na}_{2} \mathrm{SiF}_{6}, \mathrm{NaKSiF}_{6}$, $\mathrm{MgNaAlF}_{6}, \mathrm{Na}_{3} \mathrm{AlF}_{6}$ and $\mathrm{MgSiF}_{6}$.

The main corrosion agent is the free fluoride ion, which is not complexed by cations. Reactive silica decreases the free HF by forming $\mathrm{SiF}_{4}$ or $\mathrm{H}_{2} \mathrm{SiF}_{6}$. When the silica content of the PR is relatively less than the fluoride content, addition of reactive silica in the acidulation stage is recommended as a means of decreasing corrosion. This effect can be obtained also by mixing the rock with another PR that is high in reactive silica or aluminum compounds.

These effects have been demonstrated in laboratory corrosion test with $30 \% \mathrm{P}_{2} \mathrm{O}_{5}$ (phosphoric acid) to which $\mathrm{HF}$ or complex fluorine compounds, such as $\mathrm{H}_{2} \mathrm{SiF}_{6}$ were added. The test included weight loss and electrochemical techniques. The electrode potential of UNS S31600 $(0.16 \mathrm{~V})$ becomes active in the presence of $\mathrm{HF}(-0.23 \mathrm{~V})$, indicating a tendency to corrosion. The electrochemical parameters of the anodic polarization plot reveal anodic dissolution as a result of addition of $\mathrm{HF}$ and stable passive behavior in the presence of $\mathrm{H}_{2} \mathrm{SiF}_{6}$.

\subsection{Influence of $\mathrm{H}_{2} \mathrm{~S}$}

Some PRs contain as much as $1 \%$ sulfide. In acidulation the sulfide is converted to hydrogen sulfide $\left(\mathrm{H}_{2} \mathrm{~S}\right)$, a weak acid that dissociates as in the equilibrium: 


$$
\mathrm{H}_{2} \mathrm{~S} \rightleftharpoons \mathrm{H}^{+}+\mathrm{HS}^{-} \rightleftharpoons 2 \mathrm{H}^{+}+\mathrm{S}^{-}
$$

$\mathrm{H}_{2} \mathrm{~S}$ and the sulfide ion may act as reducing agents that affect the stability of the passive film on metals. Results of tests in a laboratory acidulation to which $\mathrm{H}_{2} \mathrm{~S}$ was added showed that the potential of S31600 fell slowly until it became negative, corresponding to active corrosion of the SS [15].

\subsection{Influence of minerals: Erosion-corrosion}

Erosion-corrosion (EC) is characterized in appearance by deep gullies, grooves, waves, rounded holes and valleys, exhibiting a directional pattern usually related to the direction of the fluid flow. These EC effects impair the protective film present on passive alloys, such as SS causing breakdown of passivity. On active alloys, such as CS, an active surface is maintained. In this way, the corrosion process is accelerated by mechanical removal of asperities, protuberances, and corrosion products, such as oxides or phosphates which otherwise might form a protective layer. A continuously renewed surface is generated, enhancing corrosion activity.

Corrosion, erosion and abrasion are frequent problems in chemical and mineral processing plants, leading to failures of equipment operating under severe hydrodynamic conditions. Many metals and alloys, such as CS-, SS- and Ni-base alloys, are susceptible to EC. All types of equipment that handle moving fluids, such as agitators, pumps, valves, nozzles, centrifuges, impellers and ball mills, are apt to undergo EC. The interaction between the chemical and the mechanical factors and their continuous effect on the metal surface causes EC [16].

\section{Corrosion in phosphoric acid production}

WPA plants operate under severe conditions that include elevated temperatures and rapid heat transfer, high acid concentration, agitation and circulation of liquids containing erosive suspended solids, aeration, formation of foam, and volatilization of corrosive acidic vapor that condenses on cooler metallic surfaces. Destructive corrosion results from combinations of these factors in which their combined action is greater than the sum of their separate actions.

PA is a mineral, nonoxidizing acid; its first dissociation follows the equilibrium:

$$
\mathrm{H}_{3} \mathrm{PO}_{4} \rightleftharpoons \mathrm{H}^{+}+\mathrm{H}_{2} \mathrm{PO}_{4}^{-} \mathrm{Ka}=7.52 \times 10^{-3} @ 25^{\circ} \mathrm{C}
$$

The corrosivity of pure PA solutions increases with increase in concentration to about $60 \%$ $\mathrm{H}_{3} \mathrm{PO}_{4}$ and then decreases with further increase in concentration. This behavior parallels the hydrogen ion concentration which increases with increase in acid concentration to about $50 \%$ $\mathrm{H}_{3} \mathrm{PO}_{4}$ and then decreases as the equilibrium in concentrated acid shifts to the left with further increase in acid concentration. $\mathrm{H}_{2} \mathrm{SO}_{4}$ solutions behave similarly. In both $\mathrm{PA}$ and $\mathrm{H}_{2} \mathrm{SO}_{4}$ there is a fairly good correlation between hydrogen ion concentration and the rate of corrosion.

In the WPA process, the filter acid $\left(30 \% \mathrm{P}_{2} \mathrm{O}_{5}\right)$ is concentrated and converts into the PA product $\left(52 \% \mathrm{P}_{2} \mathrm{O}_{5}\right)$. These acids are very corrosive, particularly to heat-exchanger surfaces where temperatures and velocities are high. During the concentration, part of the salts, such as 
fluoride compounds, precipitate and either from scale on the surfaces of the evaporation or remain in suspension. Fluorides are evolved with water vapor:

$$
\mathrm{H}_{2} \mathrm{SiF}_{6(\mathrm{aq})} \stackrel{\text { heat and acid }}{\longrightarrow} \mathrm{SiF}_{4(\mathrm{~g})}+2 \mathrm{HF}_{(\mathrm{g})}
$$

and $\mathrm{Cl}^{-}$ions are removed as $\mathrm{HCl}$ vapor.

The corrosivity of halide ions in pure 30 and $50 \% \mathrm{H}_{3} \mathrm{PO}_{4}$ decreases in the order $\mathrm{F}^{-}>\mathrm{Cl}^{-}>\mathrm{Br}$ in accordance with the chemical activity of the halides. In 70 and $85 \% \mathrm{H}_{3} \mathrm{PO}_{4}\left(52\right.$ and $62 \% \mathrm{P}_{2} \mathrm{O}_{5}$ ), however, the corrosivity of the halides is in the order $\mathrm{Cl}^{-}>\mathrm{F}^{-}>\mathrm{Br}$.

This result reflects the formation of stable monofluorophosphoric acid, which complexes $\mathrm{F}^{-}$ and decreases its corrosivity. The following equilibrium is established:

$$
\mathrm{H}_{3} \mathrm{PO}_{4}+\mathrm{HF} \rightleftharpoons \mathrm{H}_{2} \mathrm{PO}_{3} \mathrm{~F}+\mathrm{H}_{2} \mathrm{O}
$$

In 30 and $50 \% \mathrm{H}_{3} \mathrm{PO}_{4}$, the fluorophosphate complexes hydrolyze and yield free active $\mathrm{F}^{-}$ which promotes corrosion.

A rise in temperature increases the rate of the chemical reactions that occur in the acidulation of the PR and the concentration of the acid. Higher temperatures in the reactor accelerate the corrosion of SS agitator and pumps, and higher temperatures in the concentration stage lead to increased corrosion in heat exchangers, pipes and pumps. To minimize corrosion, nonmetallic materials are used wherever possible; these include impregnated impervious graphite, carbon bricks, Teflon coatings and fiber-glass-filled phenolic resins.

Breakdown of the passive state may occur at elevated temperatures. For example, S31600 is resistant to $85 \% \mathrm{H}_{3} \mathrm{PO}_{4}$ between 25 and $90^{\circ} \mathrm{C}$, but at higher temperatures the passive layer is damaged and corrosion increases.

Agitation produces high velocity, turbulence, impingement, cavitation and erosion; all of these increase corrosion. The destructive effect that results from the combination of mechanical wear and electrochemical corrosion usually is greater than the sum of the two factors acting separately [17].

The abrasive solids, gypsum crystals, silica, and unreacted phosphate rock in the reactor slurry which contains about 35\% solids, severely attack agitators, pump impellers and casings, and pipes, causing EC [18].

The ability of the SS- and Ni-based alloy passive films to protect the WPA plant equipment depends on their resistance to mechanical wear and their rate of regeneration when destroyed or damaged. The condition of the protective film depends on its interaction with the WPA constituents, such as $\mathrm{Cl}^{-}, \mathrm{F}^{-}$and oxidizing agents.

PR contains organic matter from fossil organisms, but its nature is not clearly defined. Its amount ranges from 0.5 to $2.3 \%$ organic carbon. Part of the organic matter may have been introduced as flotation agents that were adsorbed during beneficiation of the PR. Chemicals that control foaming, such as amines, fatty acids, and esters, are added in the acidulation step also contribute organic matter. 
The effects of these different kinds of organic matter on corrosion in WPA have not been investigated thoroughly. They affect corrosion by forming films of organic matter on metallic surfaces and decreasing or increasing corrosion according to their chemical nature and physicochemical properties, such as adsorption.

\subsection{Erosion-corrosion devices and measurements}

In equipment handling, in particular in moving corrosive fluids containing suspended solid particles, such as in slurries, the main phenomenon is EC. A particular type of localized corrosion is caused by the synergetic action of mechanical erosion and electrochemical corrosion. Several environments and equipment are affected by FC in local plants: handling and processing slurries, for example, phosphate ore washing; wet process phosphoric acid (WPA) production; periclase hydration; and carnallite and sylvinite slurries, used in potash production.

In order to understand the causes and mechanisms of EC phenomena and to measure its magnitude, the chemical and mineral industries apply different laboratory and plant devices which simulate service conditions and sometimes increase the severity of the chemical, mechanical, and hydrodynamic factors involved in EC.

Many EC-measuring devices have been designed and constructed in the last years and are frequently reported in the literature [19]. They are based, in principle, on simulation of the mechanical forces acting on the plant equipment surface and a measurement of the mechanochemical effect on a static or dynamic metallic specimen exposed to a moving fluid The FC effect is assessed by physical changes (weight, length, volumes roughness), by an electrochemical measurement or by applying both techniques simultaneously or successively.

\subsection{IMI erosion-corrosion measuring devices}

During the past years the Corrosion Laboratory of IMI (TAMI) - Institute for Research and Development was engaged in the study of corrosion in several industrial plants handling aggressive slurries and in the selection of EC-resistant alloys to be used in these plants. Since EC is the main type of corrosion encountered in these systems, it was necessary to develop devices to study and measure FC phenomena in these slurries. Accordingly, two instruments were developed, built and applied in several plants.

\subsubsection{Erosion-corrosion unit (ECU)}

This instrument simulates EC phenomena occurring in equipment handling flowing fluids, enhanced by suspended solids in slurries or entrained solids in brines. A jet of slurry or brine is impinged continuously on the curved surface of the submerged rotating specimen, through a nozzle. The instrument measures corrosion potential and instantaneous corrosion current by the polarization resistance technique in accordance with the ASTM Practice for Conducting Potentiodynamic Polarization Resistance Measurements [20].

Figure 4 presents a schematic diagram of the apparatus, which consists of three parts: the cell, the agitated vessel and the electrochemical measuring instrument. 


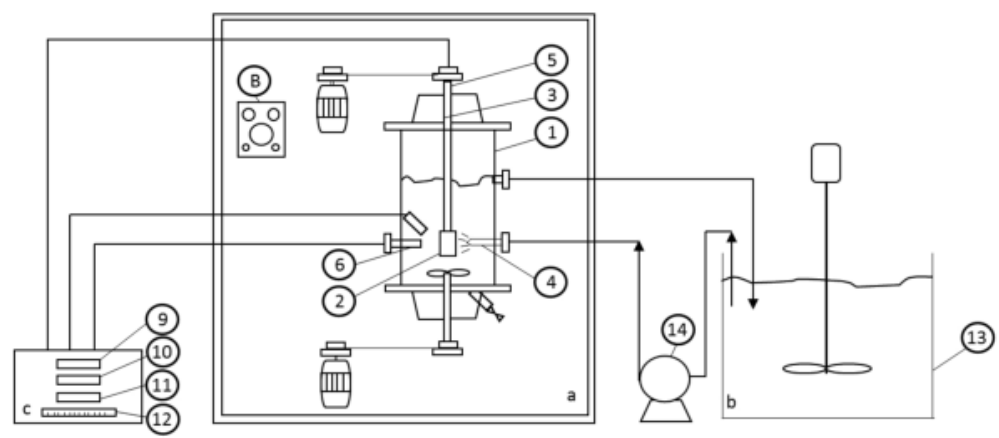

Figure 4. Diagram of erosion-corrosion unit/ECU.

The cell (a) - in a polypropylene vessel (1) (diameter $12 \mathrm{~cm}$, height $18 \mathrm{~cm}$ ) the alloy under test in the form of a cylinder (2) (diameter $20 \mathrm{~mm}$, height $6 \mathrm{~mm}$ ) is rotated about a vertical axis (3) while a jet of fluid is impinged continuously onto its curved surface through an interchangeable nozzle (4). The specimen and its mercury contact (5) are kept in place by means of a hollow rod holder. Immediately adjacent to the cylinder are an auxiliary platinum electrode (6) and a reference electrode (7).

The effects due to rotation, impingement and simultaneous rotation and impingement are determined by varying the specimen's rotational velocity and the jet's impact energy. Agitated vessel (b) - The cell is connected to an agitated slurry (B) which supplies the solids-containing fluid via a pump (14).

The electrochemical measuring instrument (c) - This instrument measures the potential (9) of the specimen and the corrosion current (10) which flows between the specimen (2) and the auxiliary electrode (6) when a fixed, 20-mV polarization potential (12) is applied to the specimen. The potential is set with respect to an $\mathrm{Ag} / \mathrm{AgCl}$ or an SCE reference electrode (6) with a polypropylene body. The instrument also measures the oxidation-reduction potential $E_{O R P}$ of the fluid. The electronic instrument was designed by Ch. Yarnitzky, Technion-Israel Institute of Technology, and built by Opal Co., Israel.

\subsubsection{Erosion-corrosion tester (ECT)}

The instrument applies rotational sliding abrasion on a static metallic specimen to simulate the corrosive wear effects of the solids-containing fluid on the surface of the equipment. The abrader material and its shape vary according to the solids type, the plant equipment and their interactions. The magnitude of the effect on electrochemical corrosion is measured by the polarization resistance technique to determine the instantaneous corrosion rate and by weight loss to assess the contribution of mechanical erosion.

The tester described in Figure 5 consists of two parts:

The EC cell (a) - the cell (3) is a polypropylene cylinder, $40-\mathrm{cm}$ high and $10 \mathrm{~cm}$ in diameter. It contains three electrodes; the working electrode(5) in the form of a disk, made from the alloy 


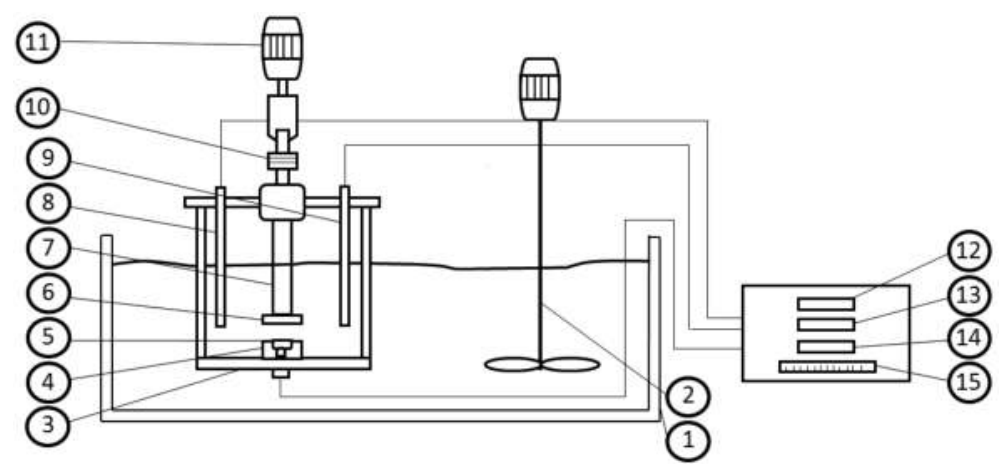

Figure 5. Diagram of erosion-corrosion tester/ECT.

under the test and the $\mathrm{Ag} / \mathrm{AgCl}$ reference electrode (8) and auxiliary platinum electrode(9), both immediately adjacent to the disk (5). The cell is immersed into the vessel (1) containing the agitated fluid (2). A cross-shaped, rigid polypropylene abrader (6) or soft rubber wiper (6a) is attached to the base of the rotating shaft (7). The solids are swept outwards, and their particles are ground on the specimen surface. The shape of the abrader (and wiper) permits the particles to be swept onto the specimen surface. The severity of the mechanical action is controlled by weights (10) mounted on the rotating shaft and by increasing the rotational velocity of the shaft.

Electrochemical measuring instrument (b) - This instrument measures the open-circuit potential (12) of the specimen and the corrosion current (13) which flows between the specimen (5) and the auxiliary electrode (9) when a fixed, small polarization potential (15) is applied to the specimen, set with respect to the reference electrode (8).

\subsection{Phosphoric acid production}

Wet process phosphoric acid (WPA) is produced by attack of phosphate ore by concentrated sulfuric acid. Impurities, such as $\mathrm{Cl}^{-}$and $\mathrm{F}^{-}$increase the corrosivity of the medium. EC appears mainly in the reaction stage, where an aggressive slurry, containing $42 \% \mathrm{PA}_{(}\left(\mathrm{H}_{2} \mathrm{PO}_{4}\right)$, $2 \%$ sulfuric acid $\left(\mathrm{H}_{2} \mathrm{SO}_{4}\right)$ and $30 \%$ solid particles (gypsum, sand, quartz, and undissolved rock) is processed at $75^{\circ} \mathrm{C}\left(167^{\circ} \mathrm{F}\right)$. The main equipment undergoing EC are the reactor agitators and pump impellers, made of an austenitic stainless steel (Fe-20Cr-25Ni-4.5Mo-1.5Cu), in short, Fe20Cr-25Ni.

The EC instruments were employed in WPA pilot plants to evaluate the corrosivity of various phosphate ores and for selection of EC-resistant alloys to be used for the fabrication of industrial plant equipment.

In an industrial plant trial, the ECT was applied to assess the effect of the addition of siliceous clays to the WPA reaction system, to complex the free hydrofluoric acid and minimize its corrosivity. AISI 316 SS high-alloyed austenitic stainless steels (Steel A, Fe-20Cr-25Ni-4.5Mo-1.5Cu, and steel B, Fe-17Cr-31Ni-3.5Mo-1.5Cu) and a Ni-base alloy (Ni-15Cr-16Mo-5Fe-2.5Co-4W) were tested. The 
results of several runs, with and without addition of clay, indicate clearly the significant reduction of EC rates in the presence of clay. The ECT was set at a rotation speed of $100 \mathrm{rpm}$ and the load on the abrader was $1.1 \mathrm{~kg} / \mathrm{cm}^{3}$. The EC rate was measured by the linear polarization resistance technique.

Anodic polarization plots were obtained at a scan rate of $60 \mathrm{mV} / \mathrm{min}$ of Fe-20Cr-25Ni alloy, obtained both on a static specimen and on a specimen being abraded by the ECT. The current fluctuations, Plot $b$, indicate a rapid sequence of breakdown of the passive film by the mechanical action of the hard, sharp particles in the slurry, followed up by the formation of a protective oxide film. On the other hand, Plot a shows stable and smaller currents. Both plots reach same value in the transpassive region. A singular behavior was reported by Matsumura et al. during erosion-corrosion measurements.

\section{Applications of phosphoric acid and phosphates}

The great variety of PRs, industrial production process and plants of PAs and its distinct applications in critical reactors of the global economy, for example, fertilizers for the agricultural grouts, treatment of metallic machinery, addition to food and beverages, products for medicinal uses and for chemical treatment in environments and industries are depicted in Figure 6. A typical PR mine is presented in Figure 7.

- Fertilizers. WPA is the most important intermediate in the fertilizer industry since it is a major constituent of triple superphosphate, ammonium phosphate and mixed NPK fertilizers. Industrialized countries produce PK and NPK fertilizers for domestic utilization and for export; they are also supplied as slow-release fertilizers, as special fertilizer for fertigation (fertilization combined with irrigation) and for foliar application. Fertilizers may be acidic, neutral or basic; their $\mathrm{pH}$ and hygroscopicity affect their corrosiveness in the presence of moisture [21].

Ground PR is directly dispersed in agricultural fields in tropical regions to neutralize the soil's natural acidity.

- Metallurgy. Chemical conversion coatings are applied on steel and aluminum surfaces for protection against corrosion. Phosphating solutions, containing PA with special active additives are employed for protection of steel vehicles, office furniture, aircraft, merchant and military ships and machinery. The phosphate coating ensures the adhesion and performance of posterior painting $[22,23]$.

Phosphate conversion coating is the most widely employed technique to afford good corrosion protection to sheet steel, in particular in the automotive industry. PA is an important industrial acid utilized in many industries. In metallurgical applications, it is used for pickling and supplementary treatment of steel sheeting used for steel car bodies and steel machinery. The phosphate layer consists of numerous crystals of different sizes, which implies the presence of voids between these crystals. Porosity is usually quite low: that is, $0.5-1.5 \%$ of phosphate coating. 


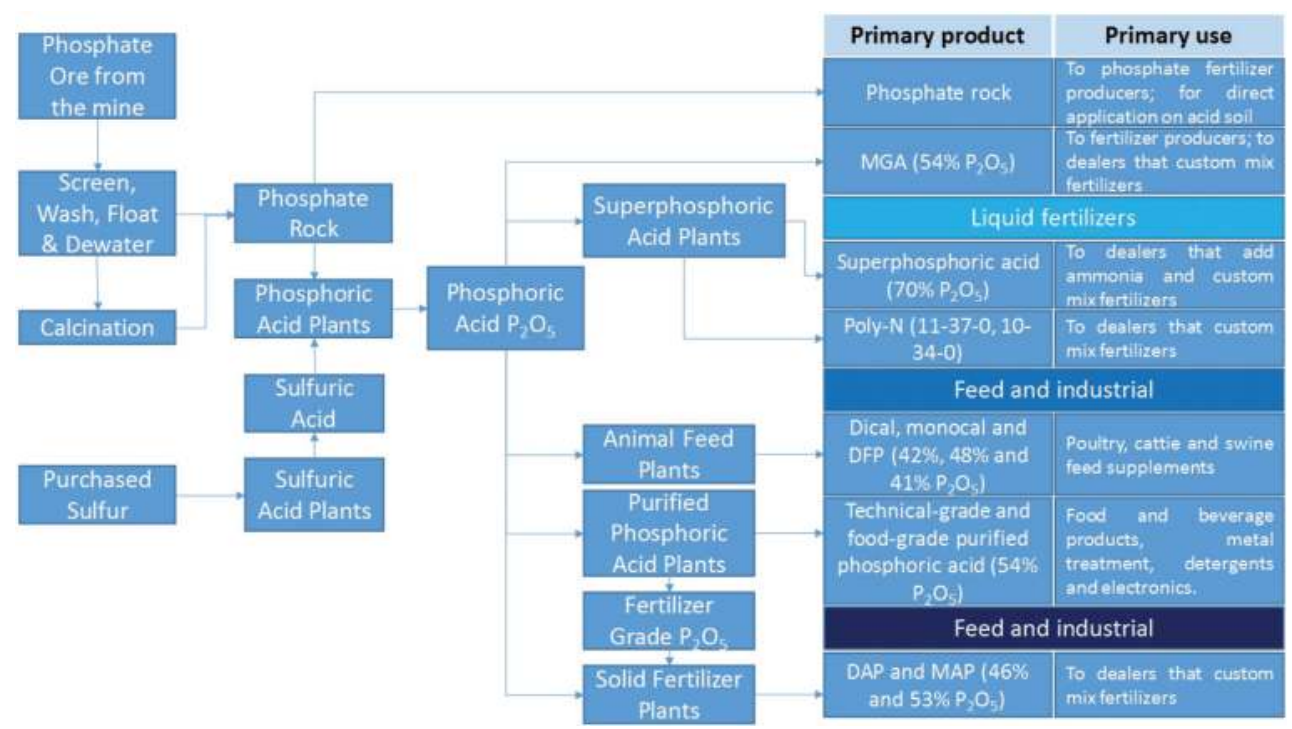

Figure 6. Phosphoric acid process, products and uses.

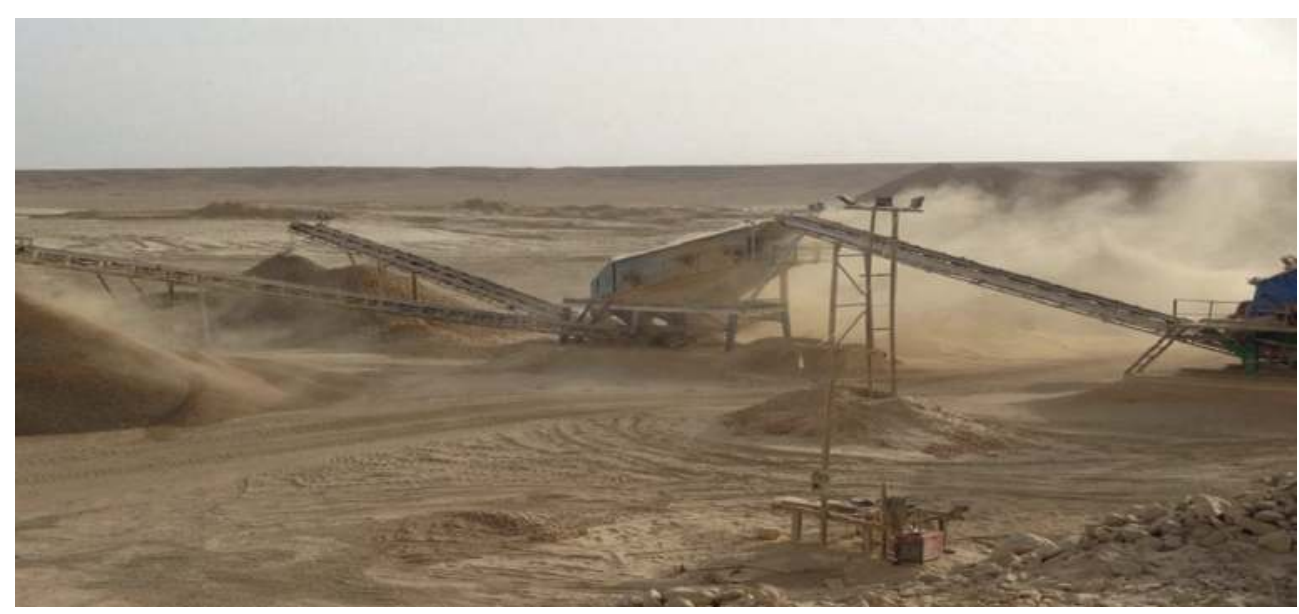

Figure 7. Phosphate rock mine.

Solutions of PA are employed for removal of rust from corroded surfaces; the black phosphate coating improves their corrosion resistance. PA solutions are utilized for cleaning and sanitation of equipment and machinery in industrial plants, for example, dairy plants; for electropolishing of SS, aluminum and copper alloys; and as a flux component in soldering. Fuel cells for electricity generation operate with PA as a liquid electrolyte.

- Chemicals. PA is used for many chemical devices and operations: to remove mineral deposits, to clean hard water stains, to etch solution nitride in micro-fabrication, in hydroponics to 
lower the $\mathrm{pH}$ of nutrient solution, as an etching agent for semiconductors, in cosmetic and skin-care products to adjust the $\mathrm{pH}$, for drinking water treatment, for preparation of synthetic rubber, for leather tanning, as an additive for varnishes, pigments and paints. It is used as an additive in the manufacture of fire bricks, fire retarding agents, ceramic colors, and as a catalyst in polypropylene polymerization and to enhance the setting action of synthetic resins. Laundry detergents contain soluble phosphates. Phosphonates, organophosphorus compounds from PA, are used as corrosion and scale inhibitors for water treatment and in the desalination industry.

- Food and beverages. Pure food grade PA [24, 25] is an additive to food sauces, mayonnaise and fruit juices, and is used to acidulate cola-type beverages. Calcium phosphate salts are added to baked goods and white, soft cheeses to avoid water segregation [26]. It is used in sugar and edible oil refining and for bacteria control in food processing. Sodium and potassium phosphate salts serve as food preservatives.

- Medicine. PA combined with zinc powder forms zinc phosphate, which is used as a dental cement. In orthodontics it is applied to clean and roughen the teeth before inserting brackets and other dental devices. Eliminating plaques and whitening the teeth are done with PA derivatives. Orthopedic metallic implants are covered with calcium phosphate to promote their integration with osseous tissue. Phosphatic cements are applied in surgery of bone systems. Also, phosphate salts are used to reduce pain in sensitive teeth.

\section{Author details}

Benjamín Valdez Salas, Michael Schorr Wiener* and Juan Ricardo Salinas Martinez

*Address all correspondence to: mschorr2000@yahoo.com

Institute of Engineering, Universidad Autónoma de Baja California, Mexicali, Baja California, México

\section{References}

[1] Dillon CP. Corrosion Control in the Chemical Process Industries. 2nd ed. Houston, TX: NACE; 1993

[2] Lehman U. Environmentally sustainable recycling of acid for pickling of stainless steel. ThyssenKrupp Techforum. 2005;1:26

[3] Gilmour R. Phosphoric Acid: Purification, Uses, Technology, and Economics. Boca Raton, FL: CRC Press; 2013

[4] Ross RW. Corrosion by phosphoric acid. In: ASM Handbook. Stephen D. Cramer and Bernard S. Covino, Corrosion: Environments and Industries. Vol. 13C. Materials Park, OH: ASM International; 2006 
[5] Schorr M. Corrosion control in WPA production using Phalaborwa igneous phosphate rocks. Phosphorous \& Potassium. 1993;184:23-33

[6] Schorr M, Valdez B. The phosphoric acid industry: Equipment, materials, and corrosion. Corrosion Reviews. 2016;34:85-102

[7] Jasinski SM. Phosphate rock. USGS Minerals Information. Personal Communication; February 2009

[8] Charrach J, Schorr M, Weintraub E. Corrosion and scaling behavior in Dead Sea basin saline waters. Corrosion Reviews. 1990;9:293-352

[9] Baniel A, Blumberg R, Alon A. Process for preparation of substantially pure phosphoric acid. US Patent: 1965. No. 3338674

[10] Baniel A. HCL Clean Tech. Jerusalem, Israel. Personal Communication; January 2015

[11] Blumberg R. Liquid-Liquid Extraction. London: Academic Press; 1998

[12] Schorr M, Valdez B, Zlatev R, Stoytcheva M. Erosion-corrosion in phosphoric acid production. Materials Performance. 2010;49:56-59

[13] Schorr M. Corrosion Manual, Corrosion Testing and Control in Fertilizer Intermediates and Products. Part One: Wet Process Phosphoric Acid. USA: International Fertilizer Development Center; 1981. pp. 1-98

[14] Shi W, Xiang S, Li YL, Yang M, Hu YN, Wang QD. Effect of temperature on electrochemical behavior of stainless steel in phosphoric acid. Applied Mechanics and Materials. 2013;351:1072-1076

[15] Bellaouchou A, Guenbour A, Benbachir A. Corrosion behavior of stainless steel in phosphoric acid polluted by sulfide ions. Corrosion. 1993;49:656-662

[16] Schorr M, Valdez B, Zlatev R, Stocycheva M. Phosphate ore processing for phosphoric acid production; classical and novel technology. Mineral Processing and Extractive Metallurgy. 2010;119:125-129

[17] Schorr M, Valdez B, Zlatev R, Santillan N. Agitator corrosion in wet phosphoric acid production. Materials Performance. 2007;46:50

[18] Hael AE, Mohammad AS, Hassan H. The effect of motion on the behavior of corrosion stainless steels in industrial phosphoric acid. Open Access Scientific Report. 2012;1:9

[19] Jang W, Pozzo RL, Iwasaki I. Technical note: Estimation of corrosive wear of grinding media by electrochemical measurements. Corrosion. 1988;44(11):836-838

[20] ASTM Standard G59-78. Standard Test Method for Conducting Potentiodynamic Polarization Resistance Measurements. West Conshohocken, PA: ASTM International; 1984

[21] Agarwal DC. Phosphoric acid production for fertilizer applications. Stainless Steel World. 2002;14:58-65 
[22] Sanchez-Tovar R, Montanes MT, Garcia-Anton J, Guenbour A. Galvanic corrosion of the base AISI 3161/micro-plasma arc welded AISI 3161 in polluted phosphoric acid media at different temperatures. International Journal of Electrochemical Science. 2011;6:55505564

[23] Santana I, Pepe A, Jimenez-Pique E, Pellice S, Ceré S. Silica-based hybrid coatings for corrosion protection of carbon steel. Part I: Effect of pretreatment with phosphoric acid. Surface and Coatings Technology. 2013;236:476-484

[24] Rotem Amfert Negev. Food grade phosphoric acid 85\%. Product specification. Rotem Amfert Negev; 2012

[25] Li YL, Xiang S, Zeng HT, Wang JP, Wang QD. The corrosion behavior of 304L and 316L stainless steels in food grade phosphoric acid solutions. Applied Mechanics and Materials. 2012;109:28-31

[26] Calcium Phosphates [Internet]. 1997-2016. Available from: http://www.chemeurope.com/ en/encyclopedia/Calcium_phosphate.html [Accessed: February 20, 2015] 
